\title{
THE GENDER ASPECTS OF CAREER DEVELOPMENT AND LEADERSHIP IN ORGANIZATIONS
}

\author{
Dea Pirtskhalaishvili \\ Ivane Javakhishvili Tbilisi State University, Georgia \\ Nino Paresashvili \\ Ivane Javakhishvili Tbilisi State University, Georgia \\ Tetiana Kulinich \\ Lviv Polytechnic National University, Ukraine
}

\begin{abstract}
The purpose of thus article is to identify the factors of leadership development in an organization and substantiate their influence on achieving gender balance in organizations, using the example of the state administration of Tbilisi (Georgia). Based on the questionnaire survey results using the method of principal components, the factors influencing the leadership development of civil servants have been determined and empirically assessed the effectiveness of management and the observance of gender balance in the management of administrations. They determined gender characteristics of leadership development using the revealed statistical differences in the formation of factors influencing leadership and professional career growth. The developed regression models provided substantiation of the qualitative characteristics of the influence of leadership development on the observance of gender balance and the effectiveness of management of organizations. They established the priority of the impact of the factors of leadership development on the observance of gender balance in the organization's management. Sobel test confirmed the mediator effect of the influence of the indicator of gender balance in management efficiency. The results obtained can be useful to develop an organizational strategy for ensuring gender diversity for career development as a factor in management effectiveness.
\end{abstract}

Keywords: organization, management, gender balance, career, men, women, gender diversity, efficiency.

DOI: http://dx.doi.org/10.15549/jeecar.v8i2.654

\section{INTRODUCTION}

For the successful functioning and development of a business, leadership, striving for career growth, and an effective management system are required. The role of a leadership position has an exceptional basis - it is leaders 
who give meaning to employees' activities, set ever-higher goals while inspiring employees to achieve them, activate business processes, and lead the company to prosperity and sustainable operations (Covarrubias Venegas, Thill \& Domnanovich, 2017). Considerable attention is currently being paid to the development of leadership in the economic system because the qualities of a leader are inherently unique and peculiar. Most importantly, they are necessary for the implementation of effective management in organizations (McCauley \& Palus, 2020). The representation of women in various leadership positions of structural divisions of organizations has become more widespread - which creates the prerequisites for fundamental changes in the interaction of representatives of both sexes in business (Liu, Wei \& Xu, 2021).

In recent years, more and more convincing evidence has been presented for the existence of differences between men and women in leadership styles, career achievement, and management Cerezo et al. (2020). They argue that men are more task-oriented, while women are more focused on interpersonal relationships. Men tend to take calculated risks and have high self-esteem, while women are more gentle and more effective in solving problems (Liu, Wei \& $\mathrm{Xu}, 2021$ ). The point is not at all which leadership style is better - "female" or "male." It is essential to take this aspect into account since it has a significant impact on the effectiveness of interactions within the organization and, therefore, on the effectiveness of the business.

As practice shows, in most countries and cultures of the world, society traditionally associates a successful leader with a "masculine" character and habits, such as assertiveness and dominance (Cerezo et al., 2020; Ljunge, 2019). Society does not accept female leadership: in this case, the usual gender norms are violated. As a result, women face more obstacles in their advancement to the higher echelons of power. At the same time, according to the results of the world's leading analytical agencies, Catalyst, companies formed by the Fortune 500 rating and on the board of directors of which there are three or more women are the leaders in the ranking in terms of business profitability. These companies were characterized by a $53 \%$ higher return on equity and $66 \%$ higher return on invested capital (an indicator that measures effective management) (Catalyst, 2013). According to McKinsey data, the studied European companies found that they perform better with the organization of more women leaders (Hunt et al., 2018).

Although many organizations and companies are gradually introducing policies aimed at achieving gender equality in working dreams, according to the World Economic Forum report, globally, the situation in the world has only worsened (World Economic Forum, 2021). It was estimated that we would need at least 170 years before achieving gender equality in the economic sector. But creating equal working conditions for women could increase global GDP by $\$ 28$ trillion by 2025 , or almost $26 \%$ compared to the conditions of standard stereotypes of leadership development and career growth in organizations (Woetzel et al., 2015). The varying proportions and variability of the sexes of leadership ensure maximum team efficiency in organizations. Therefore, the gender balance of management personnel is an essential factor in providing effective management of the organization. This study was aimed to substantiate the aspects of leadership and their influence on achieving gender balance in organizations, to increase the efficiency of management and ensure fair conditions for the development of professional careers for women on the experience of Georgia.

\section{LITERATURE REVIEW}

In modern scientific literature, gender balance in an organization means the actual or planned attitude of personnel of all categories, and real, potential career opportunities, which create conditions for equalizing the social and economic position of women and men in the management of the organization (Martin Naunton \& Peterson, 2021). Career growth and the manifestation of leadership abilities successfully implement individuals' abilities in specific types of work activities, which allows for complete selfrealization and self-affirmation due to an increase in social status. The essence of the gender approach to the management of an organization is manifested in achieving a gender balance of leaders (leading employees) (Russen, Dawson \& Madera, 2021). Consequently, the gender balance of leaders we understood as the 
optimal ratio of gender diversity among management positions at all structural divisions of the organization, which would be adequate to the number of employees (men and women), their contribution to the performance of the enterprise, and equal participation in the organizational management.

The manifestation of gender asymmetry is an inequality in the social status and the advancement of men and women's career in various social spheres of professional activity, due primarily to social stereotypes about their purpose (Stewart et al., 2021). Gender asymmetry reflects latent discrimination against women in governance. This is especially pronounced due to gender analysis of various levels of management (Kharadze \& Gulua, 2018; Martin, Naunton \& Peterson, 2021). Suppose the proportion of women in the management apparatus is significant in the lower and middle levels, and this does not surprise anyone. In that case, the representation of women at the highest level of management is minimal (Kharadze \& Gulua, 2018).

The management within the framework of gender asymmetry focuses on: differences in approaches to the team and individual leadership (Martin, Naunton \& Peterson, 2021), the characteristics of interpersonal relationships, taking into account the male and female psyche and aspects of intelligence for career development, and leadership in the organization. Analyzing the opinions of scientists, one can summarize the following differences in career development and leadership. Men are characterized by: competitiveness, a hierarchy of power; robust control over subordinates; dispassion. Women: responsive; inclined to cooperate; do not like to exercise strict control; problem-solving is based on empathy rather than rationality (Paichadze et al., 2019). In a general sense, men are expected to act with: masculinity, nobility, leadership, while from women - kindness, patience and complacence, external attractiveness and sensitivity. But numerous scientists have long proved that gender balance and leadership consolidation styles increase the efficiency of management and the activities of organizations at times. Ensuring gender diversity brings significant financial benefits to the economy at the global, regional, and national levels and individual companies (Shakil, 2021; Altuzarra, Gálvez-Gálvez \& González-Flores, 2021; Santos Silva \& Klasen, 2021). The practice has proven that women are an effective resource in management, but with still undiscovered potential for business (Bonnet, Vanek \& Chen, 2019). But then the question arises: if manifestations of gender inequality reduce the efficiency of a business, and in general, harm the wellbeing of society, why is the persistence of gender asymmetry?

As most scholars point out, the fundamental obstacle to career advancement for women is the double burden of domestic and professional responsibilities (Urchukhishvili \& Tushurashvili, 2019; Harrington \& Hall, 2007). Constraints of gender equality and why many women choose to leave careers include the gender pay gap and childcare costs (Armstrong \& Taylor, 2020). Also, the most significant destructive factor in the development of gender diversity has been formed stereotypes concerning women and men. They create invisible barriers that leave many women in jobs that are not associated with horizontal movement. As a result, women rarely manage to accumulate varied professional experience, without which they are unable to count on many leadership positions (Harrington \& Hall, 2007). Summarizing the point of view in literature, someone can argue that the difference in the position of women and men in career development and leadership is manifested in the gender gap in pay. In addition, the same will apply to differences in career prospects and needs for flexible working hours, the existence of sexual harassment, as well as male-centered work culture (García-Izquierdo, RamosVillagrasa \& Castaño, 2015; Tahir, 2020).

Since the economy determines a significant part of people's opportunities to improve their living conditions, economic policy and development decisively affect gender inequality. Thus, being in more developed economies or profitable organizations implies fewer resource constraints in career development and vice versa. But gender inequality, as already noted, depends primarily on stereotypes of society. Therefore, the nature of the economy's influence, the level of income of women and men depends on what types of activities are available to them, what professional opportunities this income 
creates, how efforts and qualifications are rewarded, and whether women and men have equal opportunities to participate. Therefore, based on the analysis of the results of scientific research on the gender factor in organizations, we have formed the following hypotheses:

Hypothesis No. 1 - the main factor-disincentive in the development of leadership among women's gender discrimination and gender stereotypes.

Hypothesis No. 2 - leadership development is influenced by the ability to maintain a balance between work and family, the degree of manifestation of which differs depending on the gender factor.

Hypothesis No. 3 - there is a directly proportional relationship between the observance of gender balance in management and management efficiency.

\section{METHODOLOGY}

The questionnaire method was used as the basic research method. The object of our research are various levels of administrations of Tbilisi districts (Georgia). The number of respondents was 429 people. - 50\% of the employees in the organizations. The survey has been conducted during January-February 2021 with voluntary and anonymous responses. The number of respondents meets the requirements for the sample size, which indicates the representativeness of the survey results. Calculated according to formula (1) (Taherdoost, 2017), the minimum sufficient size of the sample was 384 people.

$$
S_{\text {min }}=\frac{D(p)^{2} \times v \times(1-v)}{\varepsilon^{2}},
$$

where $S_{\min }$ - minimum requirements to the sufficiency of the sample population;

$D$ - standardized deviation at a confidence level $\pm 95 \%$;

$V$ - sample variation;

$\varepsilon$ - acceptable error rate.

The questionnaire consisted of 4 blocks. Block 1 is formed from general questions: gender of the respondent, place of work, position held. For these questions, the respondents had to choose the correct answer from the proposed ones.

Block 2 provided for scoring according to indicators affecting the development of leadership among men and women and the observance of gender balance in the organization's management (Smagina, 2020; Benson, 2018; Sergio et al., 2015). Block 3 - point assessment of the effective organization's management (Smagina, 2020). Block 4 - point assessment of the level of observance of gender balance in organizational management (Martin Naunton \& Peterson, 2021; Russen, Dawson \& Madera, 2021). They carried out the assessment in blocks 2-4 on a 4-point Likert scale. Grade "1" corresponded to complete disagreement with the question of the questionnaire, "2" disagreement, “3” - agreement, “4" - full agreement.

Also, we used the method of principal components (factor analysis) for the statistical processing of the results. With its help, based on the assessments of the 2nd block, the factors that influence leadership development are determined. The factor load between the indicator and the factor of leadership development in the organization was used as a criterion for assigning an indicator to the corresponding factor. The used factor loads exceeds |0.7|, which according to Menke (2018), is statistically meaningful. Using the deterministic structure of leadership development factors, their values were calculated in the Statistica 12.0 program. The sample for factor analysis was formed by the assessments of 429 respondents (which corresponds to the number of observations) on 41 questions of the questionnaire (which corresponds to the number of variables). The number of observations is more than two times the number of variables. This ensured a sufficient sample. It assessed the influence of these factors of leadership development on the gender balance in the organization's management and on the effectiveness of management by constructing one-factor linear regression models.

State administrations are not directly involved in creating added value. In this regard, we assessed the effective organization's management with non-cost indicators: the 
organization's image, the effectiveness of personnel management, customer satisfaction, staff satisfaction with leadership style, and the psychological climate in the organization (Smagina, 2020). The Management Performance Indicator $(M E)$ was calculated in the context of 10 administrations of Tbilisi districts using the formula:

$$
M E=\frac{\overline{\left(\sum_{i=1}^{n} b_{i}\right)}-\left(\sum_{i=1}^{n} b_{i}\right)_{\min }}{\left(\sum_{i=1}^{n} b_{i}\right)_{\max }-\left(\sum_{i=1}^{n} b_{i}\right)_{\min }}
$$

where $b_{i}$ - the score for an $i$-th question;

$$
\overline{\left(\sum_{i=1}^{n} b_{i}\right)}
$$

- the arithmetic means for all respondents - representatives of the relevant administration, the sum of scores for the questions of the 3rd block;

$$
\left(\sum_{i=1}^{n} b_{i}\right)_{\min }
$$

- the minimum possible amount of scores for the questions of the 3rd block.

$$
\left(\sum_{i=1}^{n} b_{i}\right)_{\min }=9
$$

. Calculated based on the fact that for all questions of the 3rd block (9 items), the respondents gave the minimum score ("1");

$$
\left(\sum_{i=1}^{n} b_{i}\right)_{\max }
$$

- the maximum possible score for the questions of the 3rd block.

$$
\left(\sum_{i=1}^{n} b_{i}\right)_{\max }=36
$$

$M E$ was measured in the range $[0 ; 1]$. A higher value corresponds to a higher management efficiency.

The indicator of gender balance $(\mathrm{GB})$ is calculated similarly to the indicator ME (according to formula 2) based on scores for the questions of the 4th block of the questionnaire. The indicator was measured in the range $[0 ; 1]$. A value of "0" corresponds to the lack of opportunities for growth and leadership development for one of the sexes. The value "1" represents men and women in senior management positions, equal conditions, and opportunities for their participation in management.

Using constructed regression models with the Sobel test, the mediator effect of the influence of gender balance in the management of an organization on management efficiency has been determined.

The t-test, cross-tabulations were used as auxiliary research methods. We used these methods to determine statistically significant differences in leadership development among men and women.

\section{RESULTS}

Based on the questionnaire results, the factor analysis made it possible to determine the factors influencing leadership development in the organization. The Kaiser criterion determines significant factors (Menke, 2018).

1.Personality factor (PERS) (variance 23.3\%). The factor explains leadership development possibilities through the prism of character traits: decisiveness, energy, initiative, courage, ambition, pride, risk-taking, self-esteem, nonconflict, tolerance.

2.Competence factor (COM) characterizes the level of education, professionalism, the intellectual and creative potential of the respondents. Their development creates the basis for the formation of authority among colleagues and the ability to occupy senior management positions. The variance of the factor was $20.1 \%$.

3. The balance between work and family $(B A L)$ (variance 16.7\%). Factor express the attitude of the respondents to the family (priority of work or family), the ability to combine family with work, parenting with work, helping spouses move up the career ladder.

4.The factor of purposefulness (PUR) determines the opportunities for leadership development through purposefulness, perseverance, striving for development and self-realization, self-criticism. The variance of the factor was $12.4 \%$. 
5.The factor of gender discrimination $(D I S)$ determines the characteristics of leadership development among men and women due to the discriminatory attitude of the organization towards women. It includes gender restrictions regarding the positions held and work duties, the right to free expression of one's own opinion, violence and harassment of women in the workplace, pay inequities for men and women, where work done by men is valued more expensively than work done by women. The factor explained $9.3 \%$ of the variance.
6.6. Motivation factor (MOT) explains $6.6 \%$ of the variance. Includes indicators, which reflect the main motives for employment: getting money, striving to be in a team, interest in professional activity, self-affirmation.

The cumulative percentage of variance for the selected factors was $88.4 \%$. According to Menke (2018), this indicates the completeness of factorization and representativeness of the analysis results (Table 1). Differences were assessed using a t-test, the values of which were calculated using the values of the factors.

Table 1: Indicators of differences in the level of factors of organizational leadership development taking into account gender feature

\begin{tabular}{|c|c|c|c|}
\hline Factor & T-test value & Factor & T-test value \\
\hline COM & 1.09 & $B A L$ & 4.12 \\
\hline PERS & 3.08 & $M O T$ & 3.93 \\
\hline PUR & 2.55 & $D I S$ & 4.69 \\
\hline
\end{tabular}

According to the level of development of the competence factor, determined no statistically significant differences between men and women-the most significant differences in education level. Despite the absence of statistically significant differences across the entire sample of female and male respondents, such a sharp difference was still observed in the higher echelons of the occupied position. Women, despite their higher education, are not represented in high positions. According to the cross-tabulation table, according to gender and level of education, the ratio for higher education respondents is as follows: Employed at the lower level: female/male 20\%/24\%; Average level: female/male 75\%/57\%; High rank: Female/Male $5 \% / 20 \%$.

For other factors, statistically significant differences were confirmed by the fact that the empirical values of the t-test are given in the table. 1 , exceed the critical 1.97 at a significance level of 0.05 .

Statistical differences in the level of development of the personality factor depending on gender are primarily due to differences in questions, which relate to the ability to take risks, ambition, and self-esteem. The t-test values were $4.29,3.38,3.21$, respectively. The excess of the empirical value over the critical value indicates the statistical significance of the revealed differences at a significance level of 0.05 .

The value of the t-criterion 2.55 shreds evidence of the higher level of development of the factor of purposefulness in men. Differences in the value of the factor are explained by the fact that the result more often guides men in work than women.

In the composition of the balance between work and family, statistical differences were recorded for questions, which relate to the need to do household chores after returning from work, support from spouses in career growth.

The answers to the question: Does the respondent receive support from his spouse for development career, and were distributed: $49.0 \%$ of women rated the support received from spouses at 3-4 points, while the same rate is higher among men and amounts to $65.4 \%$ ? In this case, too, old traditional stereotypes influence similar attitudes. As a rule, women contribute more to their husbands' career advancement 
than men, which the results presented by us confirm. The t-test value was 4.38 .

After returning home, $79.9 \%$ of the interviewed women-respondents combine family and work (the score for the question is 3-4 points), men are less likely to face such a need than women $55.8 \%$. The t-test value is 4.60 .

The statistically significant differences in the development of the work-family balance factor among men and women confirm hypothesis 2 .

The motivation factor manifests itself in different ways in the development of leadership among men and women because most women work for money. $53.4 \%$ of the interviewed women rated relevant questions at 3-4 points. The main motive for men is professional activity (39.7\% of male respondents rated relevant questions at 3-4 points) and self-affirmation
(42.8\% of male respondents rated relevant questions at 3-4 points). The empirical value of the $t$-criterion for the questions was 3.51, 4.22, 4.61 , accordingly with the critical value of the criterion 1.97. This indicates the statistical significance of the differences found.

The factor of gender discrimination revealed the most significant differences depending on the gender of the respondents. It indicates the urgency of gender discrimination and its constraining influence on the development of leadership among women.

The relationship between the factors influencing the development of leadership, the indicator of gender balance in management, the indicator of management efficiency is formalized based on the constructed regression models (Fig. 1).

Model adequacy indicators

\begin{tabular}{|l|l|l|l|}
\hline $\begin{array}{c}\text { Indicator's } \\
\text { impact }\end{array}$ & $\begin{array}{c}\text { F- } \\
\text { criterion }\end{array}$ & $\begin{array}{c}\text { t- } \\
\text { criterion }\end{array}$ & p-level \\
\hline$C O M \rightarrow G B$ & 5.61 & 2.04 & 0.08 \\
\hline$P E R S \rightarrow G B$ & 6.60 & -2.63 & 0.04 \\
\hline$P U R \rightarrow G B$ & 7.82 & -2.91 & 0.03 \\
\hline$B A L \rightarrow G B$ & 11.15 & 3.31 & 0.01 \\
\hline$M O T \rightarrow G B$ & 7.01 & -2.90 & 0.03 \\
\hline$D I S \rightarrow G B$ & 9.13 & -3.20 & 0.02 \\
\hline$C O M \rightarrow M E$ & 6.23 & 2.58 & 0.04 \\
\hline$P E R S \rightarrow M E$ & 6.12 & 2.40 & 0.05 \\
\hline$P U R \rightarrow M E$ & 7.16 & 2.89 & 0.03 \\
\hline$B A L \rightarrow M E$ & 8.80 & 3.05 & 0.02 \\
\hline$M O T \rightarrow M E$ & 6.74 & 2.84 & 0.03 \\
\hline$D I S \rightarrow M E$ & 8.11 & -3.11 & 0.02 \\
\hline$G B \rightarrow M E$ & 8.62 & 3.15 & 0.02 \\
\hline
\end{tabular}

Figure. 1: The models of the relationship between factors of leadership development, indicators of gender balance, and the organizational management efficiency

The model has been presented in the form of a directed graph. The independent variable is represented at the base of the arc (arrows) and the dependent variable at the top. The figure shows statistically significant relationships between indicators and shows the regression coefficients for independent variables (near each arc). The designation "*" means that the 
relationship is statistically significant at a significance level of $p=0.1$. The rest of the connections are shown in the figure, statistically significant at $\mathrm{p}=0.05$. The statistical significance of the regression coefficients is confirmed:

1) the F-criterion, the empirical values of which (5.61-11.15) exceed the critical 5.32 at a significance level of $\mathrm{p}=0.05$;

2) t-test for independent variables. The empirical values were | 2.04| - $3.31 \mid$, the critical value was 2.31 at a significance level of $p=0.05$ and 1.86 at a significance level of $\mathrm{p}=0.1$.

The models (Fig. 1) demonstrated the direct and indirect influence of the factors of leadership development on organizational management efficiency.

Among the factors under study, the following have a positive effect on achieving gender balance:

1) the competence factor. The development of the competencies of both sexes creates more opportunities for achieving gender balance. With a high level of competence, there is a wider choice of candidates for the highest positions and a higher probability of appointment of women;

2) the factor of balance between work and family. According to the questionnaire results, statistically significant differences in the possibilities of maintaining this balance among men and women. Since the bulk of family responsibilities now rests with women, achieving balance through partial redistribution of family responsibilities between men and women creates more opportunities for leadership development among women.

The development of these factors has a positive direct and indirect (through the indicator of gender balance) influence on management efficiency. Other factors negatively affect gender balance in governance:

3) the development of a personal factor, a factor of purposefulness, motivation contributes to the development of leadership of each respondent, regardless of gender. But because personal characteristics that correspond to these factors (purposefulness, determination, ambition, focus on the work process, and results) are more inherent in men, their development under current conditions aggravates the gender imbalance. But the development of these factors has a positive effect on management efficiency. This means that these factors need to be developed, but to a greater extent for women, to achieve gender balance and improve management efficiency.

4) The gender discrimination factor negatively affects gender balance and management efficiency.

The values of the average elasticity indicators, calculated according to the constructed models, testified that the factor of balance between work and family exerts the most significant influence on the achievement of gender balance in the organizational management (the elasticity indicator value is $1.18 \%$ ); the factor of gender discrimination (the value of the elasticity indicator is $-1.11 \%$ ), which confirms hypothesis 1 and 2 . The elasticity of the gender balance indicator from other factors was: from the factor of purposefulness $(-1.01 \%)$, the factor of motivation $(-0.96 \%)$, the personality factor $(-0.89$ $\%)$, competence factor $0.79 \%$. Negative values of elasticity indices for PERS, PUR, MOT, DIS indicate the opposite nature of the influence.

The statistical significance of the influence of the gender balance indicator on management efficiency was explained by the fact that the representation of men and women among top management brings diversity in the methods and styles of management used, views on the tasks to be solved, and increases creativity. This creates opportunities for staff expression, improves the psychological climate in the organization, and increases work efficiency. The results obtained have confirmed hypothesis 3.

The constructed models (Fig. 1) testified as a mediator factor in ensuring organizational management efficiency. This factor is the indicator of gender balance in management. To determine the statistical significance of the mediator function of this indicator, the Sobel test was used, the values of which are given in the table. 2. 
Table 2: Assessment of the mediator effect of the influence of the indicator of gender balance in organizational management efficiency

\begin{tabular}{|l|l|l|}
\hline Links between indicators & Sobel test statistic & Two-tailed probability \\
\hline$C O M \rightarrow G B \rightarrow M E$ & 3.18 & 0.0010 \\
\hline$P E R S \rightarrow G B \rightarrow M E$ & -2.96 & 0.0030 \\
\hline$P U R \rightarrow G B \rightarrow M E$ & -3.28 & 0.0010 \\
\hline$B A L \rightarrow G B \rightarrow M E$ & 3.45 & 0.0006 \\
\hline$M O T \rightarrow G B \rightarrow M E$ & -2.42 & 0.0155 \\
\hline$D I S \rightarrow G B \rightarrow M E$ & -3.32 & 0.0009 \\
\hline
\end{tabular}

The calculated Sobel test statistic values indicate that the gender balance in organizational management efficiency was statistically significant at $\mathrm{p}=0.05$ and has a mediator effect.

For the PERS, PUR, MOT factors, the obtained negative mediator effect and the positive influence of these factors on the management efficiency. This is explained by the fact that a decrease in the values of these factors for employees and a negative impact on management efficiency can be compensated for by increasing the gender balance in management.

Concerning other factors, the mediator effect of gender balance is manifested as a multiplier that enhances the positive influence of the growth of the competence factor, balance between work and family, and the positive effect of reducing the factor of gender discrimination on management efficiency.

\section{DISCUSSION AND CONCLUSION}

Based on the results of the conducted empirical research and based on the proven positive effect of gender balance on business profitability, we confirmed hypothesis 3 about the positive impact of gender diversity on the effectiveness of managing organizations by promoting leadership development among women. Since the article examined the employees of the public administration, it is not generalizable to forprofit organizations. The positive impact of achieving gender balance contributes to increasing the efficiency of management through the ability to provide services that meet the needs of both men and women. This excludes various risk factors for committing a crime or victimization to men and women in the course of professional activity. Institutionally, this means ensuring that the work environment is free from sexual or gender-based harassment and discrimination, offering equal opportunities for different men and women, depending on their qualifications and executive abilities.

State organizations, particularly the state administration of Tbilisi, are characterized by a more authoritarian approach in selecting employees and providing career opportunities. This is comparable to gender discrimination in political career development. The level of participation of women is significantly lower than the average for other sectors of the economy and business (UN Women, 2021; United Nations, 2010). Given this, overcoming gender discrimination will improve governance by increasing women's participation in managerial decision-making and service delivery in a free, fair, and inclusive manner, either directly or through legal representative institutions. Gender equality is essential to ensure free, fair, and inclusive participation because men tend to be significantly more represented in management. Also, the participation of women and the development of their leadership positions, and equal conditions for career advancement will ensure management transparency as it guarantees equal access to information and accountability mechanisms. This, in turn, can help ensure that an organization's decisions are made impartially, 
responsibly, and by existing laws and appropriate government policies.

Confirmation of hypothesis 1 indicated an insufficient level of female leadership development due to gender asymmetry in the organization. This is confirmed by modern research and is also true for commercial organizations (Liu, Wei \& Xu, 2021; Martin Naunton \& Peterson, 2021), for countries with high- and low-income levels (Altuzarra, GálvezGálvez \& González-Flores, 2021; Santos Silva \& Klasen, 2021), as well as for different cultures (Liu, Wei \& Xu, 2021; Cerezo et al., 2020; Ljunge, 2019). As part of our study, the results allowed us to conclude that jobs and decision-making powers are still distributed according to gender. Women are still far from equal to their male counterparts in terms of wages, and discrimination continues in the labor market, which is partially influenced by the nation's cultural characteristics.

The study also confirmed hypothesis \# 2, but it should note that since the object of the study was gender diversity in the state organization of Georgia, the ability to maintain a balance between family and career is especially relevant. To some extent, the imbalances are increased due to the cultural characteristics of the country. In the past decade, Georgian women have become freer and more active, including in politics and business. But stereotypes remain unchanged in a given country. The overwhelming majority of Georgian citizens believe that only a man should be the breadwinner in the family (Public Perceptions on Gender Equality in Politics and Business, 2013). In Georgian society, there are still stereotypes that a woman's place is in the kitchen, and a man decides everything. Also strong is the belief that a woman cannot be forgiven what can forgive a man, and the sphere of her self-realization is family and home. These aspects do not allow women to fully reveal their leadership abilities, develop a career, and balance their life between family and professional activity, which completely negates the possibility of achieving gender balance at the level of one organization and the level of the national economy as a whole.

Thus, the main problem of achieving gender balance in the organizations of Georgia in modern conditions is the established stereotypes of the importance of women in society. Therefore, to attract more women to those industries and positions that are not traditional, changes are needed earlier, even before they start training. Curricula can help overcome gender stereotypes, and cultural change can help women and men choose a profession from a wider range of options. Companies can change the corporate culture and perceptions that certain types of work or industries do not allow combining work and family responsibilities and should value male qualities higher. Companies can also set working time limits for both men and women and use the examples of capable women workers as role models.

The results obtained are based on the example of one country and cannot be extended to the practice of other countries with different cultural values and traditions. But given the relevance of this topic, our further research aims to compare the experience of achieving gender balance and developing organizational leadership.

\section{REFERENCES}

Altuzarra, A., Gálvez-Gálvez, C., \& GonzálezFlores, A. (2021). Is Gender Inequality a Barrier to Economic Growth? A Panel Data Analysis of Developing Countries. Sustainability, 13, 367. https://doi.org/10.3390/su13010367

Armstrong, M., \& Taylor, S. (2020). Employee wellbeing. In M. Armstrong, \& S. Taylor, Armstrong, Handbook of Human Resource Management Practice 15th Edition, 565-587.

Benson, L. E. (2018). Leadership Skills in the Digital Age: Implications for University Business Schools. Journal of Eastern European and Central Asian Research, 5(2), 10. https://doi.org/10.15549/jeecar.v5i2.217

Bonnet, F., Vanek, J., \& Chen, M. (2019). Women and Men in the Informal Economy: A Statistical Brief. Manchester, UK: WIEGO.

Catalyst. (2013). Why Diversity Matters. http://www.talent2025.org/uploads/files/Ca talyst_-Why-Diversity-Matters.pdf

Cerezo, A., Cummings, M., Holmes, M., \& Williams, C. (2020). Identity as Resistance: Identity Formation at the Intersection of Race, Gender Identity, and Sexual Orientation. Psychology of Women 
Quarterly, 44(1), 67-83.

https://doi.org/10.1177/0361684319875977

Covarrubias Venegas, B., Thill, K., \&

Domnanovich, J. (2017). The Importance of Strategic Competence in HRM: Evidence from Austria, Czech Republic, Hungary and Slovakia. Journal of Eastern European and Central Asian Research, 4(2), 11. https://doi.org/10.15549/jeecar.v4i2.145

García-Izquierdo, A.L., Ramos-Villagrasa, P.J., \& Castaño, A.M. (2015). e-Recruitment, gender discrimination, and organizational results of listed companies on the Spanish Stock Exchange. Revista de Psicología del Trabajo $y$ de las Organizaciones, 31, 3, 155-164. https://doi.org/10.1016/j.rpto.2015.06.003

Harrington, B. \& Hall, D. T. (2007). Work and Family. In B. Harrington, Career Management \& Work-Life Integration: Using Self-Assessment to Navigate Contemporary Careers (pp. 133-152). SAGE Publications.

Hunt, V., Prince, S., Dixon-Fyle, S., \& Yee, L. (2018). Delivering through Diversity. McKinsey \& Company. https://www.mckinsey.com/ /media/mckin sey/business\%20functions/organization/our \%20insights/delivering\%20through\%20divers ity/delivering-through-diversity_fullreport.ashx

Kharadze, N., \& Gulua, E. (2018). Personal Development Peculiarities on Gender Perspective in Georgia. European Journal of Multidisciplinary Studies, 111-123. http://dx.doi.org/10.26417/ejms.v3i3.p111123

Liu, Y., Wei, S., \& Xu, J. (2021). COVID-19 and Women-Led Businesses around the World. Finance Research Letters, 102012. https://doi.org/10.1016/j.frl.2021.102012

Ljunge, M. (2019). Cultural Determinants of Gender Roles: Pragmatism is an Important Factor behind Gender Equality Attitudes among Children of Immigrants. IFN Working Paper No. 1137. Research Institute of Industrial Economics. Stockholm.

Martin, A., Naunton, M., \& Peterson, G.M. (2021). Gender balance in pharmacy leadership: Are we making progress? Research in Social and Administrative Pharmacy, 17, 4, 694-700. https://doi.org/10.1016/j.sapharm.2020.05.0
31

McCauley, C.D., \& Palus, C.J. (2020). Developing the theory and practice of leadership development: A relational view. The Leadership Quarterly, 101456. https://doi.org/10.1016/j.leaqua.2020.10145 6

Menke, W. (2018). Factor Analysis. Geophysical Data Analysis (Fourth Edition). New York: Academic Press, 207-222.

Paichadze, N., Kharadze, N., Giorgobiani, M., \& Nikvashvili, M. (2019). Career Management Trends in Terms of Gender. 17th International Conference on Social Sciences, 124-143. Murcia: European Center for Science Education and Research. http://dx.doi.org/10.26417/ejes.v5i1.p225257

Public Perceptions on Gender Equality in Politics and Business. (2013). Tbilisi.

https://www.ge.undp.org/content/georgia/e n/home/library/democratic_governance/pub lic-perceptions-on-gender-equality-inpolitics-and-business.html

Russen, M., Dawson, M., \& Madera, J.M. (2021). Gender diversity in hospitality and tourism top management teams: A systematic review of the last 10 years. International Journal of Hospitality Management, 95, 102942. https://doi.org/10.1016/j.ijhm.2021.102942

Santos Silva, M., \& Klasen, S. (2021). Gender inequality as a barrier to economic growth: a review of the theoretical literature. $\operatorname{ReV}$ Econ Household. https://doi.org/10.1007/s11150-020-095356

Sergio, R. P., Gonzales-Lim Ormita, L. A., Dungca, A. L., \& Ocampo-Gonzales, J. (2015). Emotional Intelligence, Work/Family Conflict, and Work Values among Customer Service Representatives: Basis for Organizational Support. Journal of Eastern European and Central Asian Research, 2(1). https://doi.org/10.15549/jeecar.v2i1.86

Shakil, MH (2021). Environmental, social and governance performance and financial risk: Moderating role of ESG controversies and board gender diversity. Resources Policy, 72, 102144. 
https://doi.org/10.1016/j.resourpol.2021.10 2144

Smagina, O. (2020). Gender and job satisfaction in higher education institution: Case study from Uzbekistan. Journal of Eastern European and Central Asian Research, 72), 219-229.

https://doi.org/10.15549/jeecar.v7i2.392.

Stewart, R., Wright, B., Smith, L., Roberts, S., \& Russell, N. (2021). Gendered stereotypes and norms: A systematic review of interventions designed to shift attitudes and behavior. Heliyon, 7, 4, e06660.

https://doi.org/10.1016/j.heliyon.2021.e066 60

Taherdoost, H. (2017). Determining Sample Size; How to Calculate Survey Sample Size. International Journal of Economics and Management Systems, 2, 237-239.

Tahir, M.W. (2020). Combating discrimination at workplaces through mainstreaming 'gender' and 'integration' needs in legislation: Testing a new analytical framework in Germany and Sweden. Women's Studies International Forum, 81, 102380. https://doi.org/10.1016/j.wsif.2020.102380

UN Women. (2021). Georgia. Retrieved April 30, 2021, from https://eca.unwomen.org/en/where-weare/georgia

United Nations. (2010). Enhancing the role and participation of women in political processes. Bratislava.

https://www.un.org/ru/development/survey s/docs/women_polit_participation.pdf

Urchukhishvili, G. \& Tushurashvili, G. (2019). Career in Civil Service and Gender Equality. Tbilisi: produced by the Institute for Development of Freedom of Information (IDFI) with the support of the United Nations Development Program (UNDP) and the aid of the UK Government. https://idfi.ge/public/upload/Gender/Gender _ENG\%20PRINT1.pdf

Woetzel, J., Madgavkar, A., Ellingrud, K., Labaye, E., Devillard, S., Kutcher, E., Manyika, J., Dobbs, R., \& Krishnan, M. (2015). The Power of Parity: How Advancing Women's Equality Can Add \$12 Trillion to Global Growth. Global Institute. https://conectadas.org/wp-
content/uploads/2018/05/MGI-Power-ofparity_Executive-summary_September2015-1.pdf

World Economic Forum. (2021). Global Gender Gap Report 2021. https://gtmarket.ru/ratings/global-gendergap-index

\section{ABOUT THE AUTHORS}

Dea Pirtskhalaishvili, email: dea.pirtskhalaishvili@tsu.ge

Dea Pirtskhalaishvili, is a postgraduate student at Ivane Javakhishvili Tbilisi State University, Georgia

Nino Paresashvili, Ph.D. is an Associate Professor at Ivane Javakhishvili Tbilisi State University, Georgia

Tetiana Kulinich, Ph.D., is an Associate Professor, Lviv Polytechnic National University, Ukraine 